\title{
LA CARTA DE PABLO A LOS FILIPENSES DESDE LA PERSPECTIVA DE UN PRISIONERO POLÍTICO
}

La carta de Pablo a los Filipenses es un escrito muy apreciado entre los cristianos. Se subraya la reiteración del gozo de Pablo y su amor hacia la comunidad cristiana de Filipos, sus destinatarios. Sin embargo, a menudo se olvida que la carta ha sido escrita desde una prisión, con todas las implicaciones que eso conlleva. Si no se toma en cuenta el lugar desde donde se escribe, la carta fácilmente se puede espiritualizar y ver como una carta amorosa inofensiva. Robin Scroggs escribe al respecto que el apóstol:

... ha sido arrestado por un funcionario romano debido a una acusación por algún cargo lel cual ha sido presentado contra él por ciudadanos particulares, quienes han ganado el proceso, que lleva a la condena a muerte). En el tiempo que escribió la carta, Pablo no sabe cuál será el veredicto del juicio. La incertidumbre desesperada entre la vida y la muerte permea la primera sección de la carta, y necesariamente se trasluce en todos los temas que trata Pablo. Sin embargo, algunos comentaristas parecen pensar que Pablo escribió su carta en un paseo de domingo ${ }^{1}$.

Scroggs tiene razón, el contenido de la carta nos sorprenderá si la leemos desde el contexto desde donde se escribe y tomamos en serio las investigaciones que se han hecho y se siguen haciendo sobre la situación de las cárceles y los prisioneros en el tiempo de Pablo. Si tomamos en cuenta este contexto para el análisis del discurso, probablemente lograremos

1 «Paul the Prisoner: Political Asceticism in the Letter to the Philippians», en L. VaAge / V. Wimbush (eds.), Asceticism and the New Testament. New York - London, Routledge, 1999, p. 187. La traducción es mía. 
entender mejor algunas frases o palabras incomprensibles, algunos vacíos y otras estrategias propias de los prisioneros, condicionados por la censura.

No hay duda de que Pablo escribió la carta a los Filipenses desde una prisión. Él fue encarcelado por sus ideas, no por tener deudas o ser un criminal. Escribe como un prisionero que en tiempos modernos se le llamaría «prisionero político». Hay algunos comentarios o aportes, poquísimos, que toman en serio esta situación particular de Pablo, hablaremos de ellos más adelante. Para nosotros, esta realidad es vital porque, de acuerdo a nuestra lectura, el hecho de que escriba desde la cárcel, en espera de una probable condena a muerte (Flp 1,20), condiciona todo el discurso de la carta. Podemos afirmar que la prisión es el lugar teológico (locus teológico) desde donde reflexiona sobre su visión cristológica.

El artículo tiene dos partes; la primera tiene que ver con la prisión, en esta parte veremos: la experiencia de Pablo de acuerdo a sus cartas y a Hechos de los Apóstoles; las implicaciones de estar en prisión, en cadenas; las implicaciones de escribir cartas desde la prisión. La segunda parte del artículo está dedicada al análisis de la carta; veremos: el contexto global inmediato; la situación física y emocional de Pablo en cadenas; su teología que surge de la prisión y las exhortaciones a sus destinatarios condicionadas por el contexto.

\section{Pablo y su experiencia en las prisiones según su testimonio y el de Hechos de los Apóstoles}

Sabemos que Pablo estuvo encarcelado porque él mismo lo dice en sus cartas cuando estuvo libre ( 2 Cor 11,23; 2 Cor 8,9), y porque es explícito sobre sus cadenas cuando escribe cartas desde la prisión, como Filipenses $(1,7.17)$ y Filemón $(1.9)^{2}$. Lucas, en Hechos de los Apóstoles, lo corrobora años más tarde (85 EC) cuando narra los hechos de la vida de Pablo. Clemente de Roma afirma en su Primera carta a los Corintios que Pablo fue encarcelado siete veces $(1 \mathrm{Cl} 5,6)^{3}$.

\footnotetext{
${ }^{2}$ Es interesante que tres de las cartas déuteropaulinas son escritas también desde la prisión: Colosenses, Efesios, 2 Timoteo. Esto indica que su condición de prisionero marcó a las primeras comunidades relacionadas con él; Hechos lo comprueba.

${ }^{3}$ Eptakis desma. La traducción de Daniel Ruiz Bueno está equivocada al traducir «seis veces». D. Ruiz Bueno, Padres Apostólicos. Texto bilingüe completo. Madrid, BAC, ${ }^{21977, ~ p . ~} 182$.
} 
A pesar de que la intencionalidad del autor de Hechos es presentar una cara positiva del Imperio romano ${ }^{4}$, no pueden pasar inadvertidos muchos de los sufrimientos de Pablo como un prisionero por causa de sus ideas. En Hechos leemos una larga lista de dificultades que Pablo tuvo durante sus viajes misioneros al Asia Menor y más tarde en Palestina. En Filipos fue desnudado, torturado y encarcelado con cepo, porque su predicación tocaba intereses económicos (Hch 16,22-24); en Tesalónica también fue arrestado por sus ideas (17,6-9); en Corinto fue llevado al tribunal frente al procónsul Galión por discusiones doctrinarias (Hch 18,12.16); en Éfeso casi padeció un linchamiento, pero sus seguidores y algunas autoridades le aconsejaron que se escondiera (19,23-41). En Jerusalén, al llegar, la gente del lugar lo agarró para matarlo $(21,31)$, pero militares romanos lo pusieron preso $(21,33)$, allí el tribuno lo quiso torturar con azotes en el interrogatorio para sacarle información $(22,24)$ por la gran protesta de los de Jerusalén. Poco antes, el tribuno lo había confundido con un terrorista egipcio que se había ido al desierto con cuatro mil sicarios $(21,38)$. Pero Pablo se libró de los azotes al declarar que era ciudadano romano $(22,25-29)$, solamente lo dejaron encadenado (22,30). En Cesarea, el gobernador Félix lo dejó dos años en la cárcel, sin juicio, esperando un soborno que nunca llegó $(24,26-27)$, esto en contra de la ley Juliana (Lex Iulia), que prohibía los sobornos, pero que en la práctica eran muy comunes ${ }^{5}$. Su sucesor, Porcio Festo, pensó reenviarlo a Jerusalén para que fuese juzgado allá, pero Pablo, al ver el peligro de ser asesinado, apeló al César (25,10-12). Se lo llevaron preso a Roma en un barco junto con otros prisioneros (27,1-2); al naufragar el barco, los soldados casi matan a todos los prisioneros para que no escaparan $(27,42)$. El libro de Hechos termina dejando a Pablo en cadenas por dos años, bajo la vigilancia de un soldado $(28,16)$ en una casa alquilada $(28,30)$. Esta versión de Hechos deja ver los padecimientos del apóstol en las prisiones antiguas.

Pablo, en sus cartas auténticas, a diferencia del autor de Hechos, es parco para hablar sobre su situación como prisionero; simplemente se presenta como prisionero por la causa de Cristo en Flm 1, además de anciano, prisionero (9); y en Filipenses lo alude explícitamente en 1,7, cuando agradece la solidaridad a sus destinatarios de Filipos y prepara su defensa, y en 1,13 , cuando alude a sus cadenas y a la guardia del pretorio. Habría que leer entre líneas sobre sus sufrimientos, como en Flp 1,17, donde informa que algunos buscan añadir más dolor a sus cadenas ( $\delta \in \sigma \mu o i \varsigma)$; además podría

${ }^{4}$ Cf. K. Wengst, Pax romana and the Peace of Jesus Christ. London, SCM Press, 1987, pp. 89-105.

${ }^{5}$ E. TÁmez, Contra toda condena. San José, DEI, 1991, p. 64, nota n. 71. 
ser que haya pasado hambre en la cárcel, según Flp 4,12. Pero si uno lee la carta en su conjunto sabiendo desde dónde se escribe, en varias partes se escucha la angustia y el grito de un prisionero que vive la incertidumbre de una probable condena a muerte, como por ejemplo Flp 1,18-26.

Curiosamente, en las cartas pospaulinas, catalogadas como pseudoepigráficas, encontramos más indicios, como en 2 Tim 2,9, donde el Apóstol afirma que sufre la cárcel $(\delta \in \sigma \mu \omega \hat{\omega} \nu)$ como un criminal, y en 1,16, donde

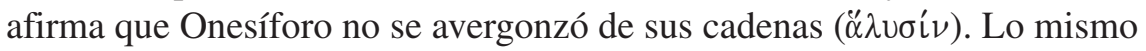
podemos ver en Col 4,18, donde suplica a sus destinatarios que se acuerden de sus cadenas $(\delta \in \sigma \mu \omega \hat{\omega})$. Esto puede explicarse por el hecho de que son pseudoepigráficas, escritas muchos años después. Cuando el mismo Apóstol escribe sus cartas desde la prisión, sabe que debe cuidarse mucho por la censura que se hacía a los escritos salidos de la cárcel, fueran cartas, poemas o declaraciones. Así pues, cuando Pablo habla de sus sufrimientos y torturas en la cárcel, lo hace cuando está libre; podemos verlo en 2 Cor 1,810: allí habla de los tremendos sufrimientos que tuvo en Asia, al punto de pensar que iba a morir. Allí menciona que salió libre de una sentencia a muerte, probablemente se trataba de un encarcelamiento en Éfeso, desde donde tal vez escribió la carta a los Filipenses. Más abajo trataremos el asunto del lugar donde Pablo escribió la carta.

Estas son sus palabras:

Porque, hermanos, no queremos que ignoréis acerca de nuestra tribulación que nos sobrevino en Asia; pues fuimos abrumados sobremanera más allá de nuestras fuerzas, de tal modo que aun perdimos la esperanza de conservar la vida. Pero tuvimos en nosotros mismos sentencia de muerte, para que no confiásemos en nosotros mismos, sino en Dios, que resucita a los muertos; el cual nos libró, y nos libra, y en quien esperamos que aún nos librará de tan gran muerte (2 Cor 1,8-10).

Pablo sí habla aquí con realismo de su experiencia en la cárcel, la cual difiere un poco de Hch 28,30-31, donde señala que Pablo tenía la custodia en una casa alquilada, y desde allí predicaba con libertad, recibiendo visitas y sin impedimento. Angela Standhartinger afirma que es imposible que Pablo tuviera el privilegio de una custodia fuera de la cárcel en una casa alquilada, como aparece en Hch 28, pues la libera custodia era un privilegio reservado a la clase senatorial y a las altas élites de las provincias ${ }^{6}$.

${ }^{6}$ «Aus der Welt eines Gefangenen. Die Kommunikationsstruktur des Philipperbriefs im Spiegel seiner Abfassungssituation», en Novum Testamentum 55 (2013), p. 143. 
En las investigaciones actuales contamos con varios aportes muy importantes que toman en cuenta las prisiones y los escritos de prisiones en la antigüedad. Entre ellos: Angela Standhartinger ${ }^{7}$, Craig S. Wansink ${ }^{8}$, Richard Cassidy ${ }^{9}$ y James C. Scott ${ }^{10}$. Estos aportes son indispensables para entender el discurso de Pablo plasmado en su carta, ya que describen el contexto romano de las prisiones, los prisioneros, el problema de los escritos desde la prisión debido a la censura y el riesgo de los destinatarios de las cartas de las prisiones. De esos aportes me referiré en el próximo apartado.

\subsection{Estar en la cárcel: implicaciones}

Contamos con escasísima literatura de cartas antiguas extrabíblicas salidas de la prisión, algunos papiros que no ayudan mucho ${ }^{11}$; también hay testimonios valiosos de algunos prisioneros del primer siglo y afirmaciones de historiadores de la antigüedad sobre la situación de las cárceles. En estos testimonios se basan los libros mencionados antes.

Craig S. Wansink, en su libro Chained in Christ, desarrolla un excelente análisis sobre la situación de las cárceles antiguas y los prisioneros ${ }^{12}$. Si bien, como él indica, arqueológicamente hay poca evidencia sobre las prisiones antiguas, existe suficiente evidencia de fuentes literarias (p. 39) que apuntan a lo mismo: la cárcel era un espacio reducido, abarrotado de prisioneros, con poco aire, bastante oscuro, asqueroso, por lo tanto dañino para la salud, donde las enfermedades abundaban (pp. 33-40).

Los sufrimientos en las prisiones eran muchos, además de las pobres condiciones mencionadas arriba, como el espacio sucio, oscuro y con falta de aire, que se hacía difícil respirar, padecían torturas físicas como golpes y azotes, y torturas mentales como insultos y amenazas. El estar encadenado no era raro. Tenemos el caso de Antiphilus, quien dormía en el suelo,

\footnotetext{
${ }^{7}$ Ibid., pp. 140-167.

${ }^{8}$ Chained in Christ. The Experience and Rhetoric of Paul's Imprisonments. JSNT S. Sheffield, Academic Press, 1996.

9 Paul in Chains. Roman imprisonment and the Letters of St. Paul, New York, A Herder ad Herder Book/The Crossroad Publishing Co., 2001.

${ }^{10}$ Domination and the Arts of Resistance. Hidden Transcripts. New Haven - London, Yale University Press, 1990.

${ }^{11}$ A. Standhartinger, «Aus der Welt eines Gefangenen», a. c., p. 155.

${ }^{12}$ C. WANSINK, Chained in Christ, o. C., pp. 33-40.
} 
y de noche le ponían cadenas en los pies, mientras que de día usaba un collar de hierro alrededor del cuello y grilletes en el brazo o mano (manacle). Difícilmente dormía, no solo por la incomodidad, sino por los ruidos de las cadenas de hierro de los prisioneros. Tal fue su cambio físico que su amigo Demetrio, cuando lo fue a ver, no lo pudo reconocer ${ }^{13}$.

En algunos casos, las condiciones eran tan terribles que morir era una salida más digna. Según las investigaciones de Wansink y de Cassidy, muchos romanos prefirieron el suicidio ${ }^{14}$ a seguir viviendo la humillación de la cárcel. Wansink, basándose en Dión Casio y Suetonio, afirma que, en algunos casos, la ejecución se retrasaba para que el prisionero sufriera más tiempo ${ }^{15}$.

En cuanto a la cantidad de prisioneros y el tamaño de las cárceles, no hay muchos datos, pero en un relato se habla de un espacio donde cabían nueve colchones y había cincuenta prisioneros ${ }^{16}$.

Estos sufrimientos leídos en fuentes extrabíblicas los encontramos también en Hechos; como mencionamos arriba, Pablo fue arrestado en Filipos por perjudicar el negocio de unos explotadores de una niña adivina. Fue denunciado, llevado a los tribunales y allí fue desnudado, azotado, arrojado a la cárcel, asegurado con un cepo en los pies y puesto en la parte más horrenda de la prisión, la parte interior (Hch 16,22-24). A este cuarto también se refieren las fuentes extrabíblicas.

A través de esas fuentes literarias se deduce que había un espacio o cuarto interior dentro de la prisión. En los estudios de Wansink queda claro que no había celdas individuales, sino que todos los prisioneros estaban juntos y con cadenas en el mismo espacio. Lo que había era un cuarto metido en la parte más baja de la prisión; se dice que era el más temible y el más oscuro. Allí eran enviados los presos ya sea por castigo o para mayor seguridad. Wansink señala cómo varios mártires cristianos fueron mandados al cuarto interior por distintas razones, algunos por no dar soborno a los carceleros, como fue el caso de Pionius ${ }^{17}$. En Roma todavía existe la ruina de una prisión antigua donde hay una tradición que afirma que Pablo

13 lbid., p. 36.

14 R. CAssidy, Paul in Chains, o. c., p. 46.

${ }^{15}$ Los historiadores cuentan el caso de un prisionero que le suplicó al emperador Tiberio que lo ejecutaran ya, pero que el emperador le respondió: «Aún no soy tu amigo». C. Wansink, Chained in Christ, o. c., p. 32.

${ }^{16}$ Cf. R. CAssidy, Paul in Chains, o. c., p. 38. Se trata del relato de Diodoro sobre el prisionero Perseo, de la prisión de Alba Fucens (Dıodorus, Library of History 31.9.1-14).

${ }^{17}$ C. WANSINk, Chained in Christ, o. c., p. 37. 
fue decapitado en ella. Se trata justamente de este cuarto ubicado en la parte más baja del presidio, más de tres metros y medio bajo el nivel del suelo de la cárcel, según lo indica el historiador romano Salustio (86 AEC - ca. 35 AEC) $)^{18}$; en la antigüedad, esa celda o cuarto era llamado tullianum 19.

Richard Cassidy, en su conocido libro Paul in Chains, aclara que la severidad del encarcelamiento dependía del tipo de custodia asignado. La ley establecía tres tipos ${ }^{20}$. La más cruel era la cárcel (carcer) propiamente dicha, le seguía la llamada custodia militar (custodia militaris) y después la custodia libre (custodia libera) ${ }^{21}$. De la cárcel ya se habló antes. La custodia militar consistía en encadenar al prisionero a uno o dos soldados, los cuales se encargaban de custodiarlo bajo la dirección de un centurión. La mayoría de los estudiosos están de acuerdo en afirmar que Pablo sufrió la custodia militar, muy parecida a la de Herodes Agripa I, narrada por Josefo. A través de la narración del historiador se infiere que no era fácil contar con un baño diario y que los soldados a los cuales el prisionero estaba encadenado podían hacerle la vida imposible, ya que estar atado a él las veinticuatro horas del día dependía mucho del carácter del soldado para sobrellevar la carga de la prisión. También los prisioneros en custodia militar podían recibir visitas con donaciones como alimentos y ropa. En cuanto a las cadenas, era muy incómodo para el prisionero debido al peso del hierro. Se empleaban cadenas en los brazos y manos (manacles) o en las piernas y pies (pedicles) ${ }^{22}$.

El buen o mal trato también dependía del estatus del preso. Regularmente, como es de esperar, había parcialidad a favor del preso con influencia, poder, riqueza. Las leyes de iure y de facto dejan ver el prejuicio y parcialidad de los jueces y oficiales romanos ${ }^{23}$.

El encarcelamiento de Pablo, según podemos observarlo en Filemón y Filipenses, corresponde más bien a este tipo y no al de custodia libera, según Hch 28,30-31. Este tipo de custodia libre, reservado a las élites, permitía no estar encadenado y ser supervisado por un miembro de la familia ${ }^{24}$. Pablo, un

${ }^{18}$ En La conjuración de Catilina. Madrid, Espasa-Calpe, 81986.

${ }^{19}$ C. WANSINK, Chained in Christ, o. c., p. 40.

${ }^{20}$ Esto fue en tiempos del emperador Justiniano, muchos años después, pero seguramente ya existían estas modalidades en la época de Pablo. Lo deducimos por testimonios bíblicos y extrabíblicos.

${ }^{21}$ R. CAssidy, Paul in Chains, o. c., p 37.

22 Ibid., p. 46.

${ }^{23}$ E. TÁmez, Contra toda condena, o. c., p. 63.

${ }^{24}$ R. CAssidy, Paul in Chains, o. c., p. 42. 
artesano no perteneciente a la clase senatorial ni ecuestre, ni a la clase aristocrática de la provincia, podía no sufrir el primer tipo de cárcel, pero difícilmente sería un prisionero bajo la custodia libre ${ }^{25}$. La custodia militar era menos cruel que la cárcel del primer tipo, pero eso no quita el sufrimiento que padeció Pablo bajo la custodia militar, vigilado por soldados y encadenado permanentemente a ellos. Pablo tenía que depender del estado de humor y del carácter o temperamento del soldado o soldados a los cuales estaba atado, lo cual no era fácil. La práctica de estar encadenado a uno o dos soldados significaba vergüenza y humillación ${ }^{26}$, cosa grave en una cultura regida por los patrones de honor y vergüenza. Cassidy, basado en Séneca, contemporáneo de Nerón y de Pablo, señala que la custodia militar era común en el tiempo de Pablo ${ }^{27}$. En 2 Tim 1,16, el autor agradece que Onesíforo no se avergonzara de sus cadenas; mientras que Figelo y Hermógenes lo abandonaron. Todo ello nos lleva a concluir que no es una exageración cuando Pablo habla a los corintios con crudeza sobre su terrible experiencia en la prisión en Asia (2 Cor 1,8-10). También nos lleva a pensar que sus escritos de alguna forma están condicionados por su situación vital en el momento que los escribe.

A propósito de Onesíforo (2 Tim 1,16) y de los filipenses, que socorrieron asiduamente a Pablo en la prisión, debemos recordar que la situación de los prisioneros en cuanto a alimentos, ayudas económicas y apoyo moral era de vital importancia. En su carta a los Filipenses, Pablo no oculta la gran alegría de recibir la ayuda que la comunidad de Filipos le ha dado a través de Epafrodito. Quienes hacían que la situación en cadenas fuera un poco más tolerante eran los familiares o amigos, llevándoles comida, ropa, además del consuelo de tenerles cerca y conversar y ayudarles a preparar su defensa $(2$ Tim 4,16). Los cristianos presos, en los orígenes del cristianismo, tenían la ventaja de contar con hermanos y hermanas de la ekklesía que se encargaban de atenderlos. Contamos con varias cartas bíblicas y extrabíblicas donde vemos la asistencia de los hermanos a prisioneros por la causa de Cristo. En cuanto a evidencia bíblica, lo observamos en la carta de Pablo a Filemón, cuando menciona la compañía y colaboración de Marcos, Aristarco, Dimas y Lucas, además de Timoteo y Onésimo. Lo mismo observamos en Filipenses, pues el apóstol tiene el gran apoyo de Timoteo (Flp 2,19-24), además de Epafrodito (4,10-19; 2,30), quien vino desde Filipos de parte de las comunidades para traerle la ayuda económica y para asistirlo.

\footnotetext{
${ }^{25}$ A. Standhartinger, «Aus der Welt eines Gefangenen», a. c., pp. 142-143.

${ }^{26}$ R. CAssidy, Paul in Chains, o. c., p. 48; cf. 2 Tim 1,8.

${ }^{27}$ Ibid.
} 
Pero también se da el caso contario, el del abandono del prisionero. El autor de 2 Tim, prisionero en Roma (1,17), escribe que Demas le ha dejado (2 Tim 4,10), y otros de Asia (Figelo y Hermógenes), a excepción de Onesífero, se han avergonzado de sus cadenas y lo han abandonado.

Una cuestión importante de mencionar tiene que ver con los cargos contra los prisioneros. Se sabe que los delitos comunes eran por hurto, daños a terceros, deudas, ultrajes, etc.; también había delitos públicos, como los de subversión (seditio) o traición al emperador, llamado en latín maiestas. Según algunos estudiosos, Pablo seguramente fue metido a la cárcel o por sedición o por traición al emperador (maiestas), que es casi lo mismo ${ }^{28}$. Este cargo, dice Cassidy, «en sus orígenes era un cargo contra aquellos metidos en actividades subversivas, como revueltas militares, o por colaborar con el enemigo» ${ }^{29}$, sin embargo, más tarde se convirtió en «cualquier tipo de conducta que dañaba la majestad del pueblo romano», es decir, del emperador. Pero, como confirma Cassidy, lo que en un principio correspondía a una amenaza real de conspiración después se volvió una excusa para llevar a la cárcel a las personas ante el menor detalle o gesto de difamación contra el emperador. Este cambio se inició en tiempos de Augusto, cuando se empezó a incluir la difamación dentro de la lex maiestas ${ }^{30}$; no obstante, el abuso se profundizó más en tiempos del emperador Tiberio, pero especialmente en el tiempo de Nerón ${ }^{31}$. Pablo vivió justamente bajo el emperador Nerón.

\subsection{Escribir desde la cárcel: implicaciones}

Angela Standhartinger tiene razón al decir que poca atención se ha dado a lo que significa escribir desde la prisión ${ }^{32}$. Los debates se concen-

${ }^{28}$ Cf. ibid., pp. 55-67. No hay plena seguridad al respecto. Hechos habla de tumultos causados por la predicación de Pablo, que causaron el arresto. Pero algunas de las acusaciones son muy comprometedoras, como la que ocurrió en Tesalónica, cuando Pablo fue acusado de actuar contra los decretos del emperador y de afirmar que había otro rey (Hch 17.7).

${ }^{29}$ Ibid., p. 56.

${ }^{30}$ Cf. N. Santos Yanguas, «Acusaciones de alta traición en Roma en la época de Tiberio». Universidad de Oviedo: Dialnet.

${ }^{31}$ Cf. los casos ridículos narrados por CASsIDY, o. C.

${ }^{32}$ A. Standhartinger estudia en su artículo las condiciones de las prisiones, los riesgos y estrategias de quienes escriben y los problemas en la recepción de la carta, lo cual incluye los riesgos y la tarea de la descodificación del discurso de la carta. 
tran más en discutir el lugar geográfico desde donde escribe Pablo su carta a los Filipenses: si desde Éfeso, Roma o Cesarea. Sin embargo, si bien es importante tener en mente un lugar geográfico, más importante es visualizar el espacio físico de la prisión desde donde el autor escribe la carta. Es decir, tomar en cuenta las dificultades, los riesgos, la censura y las consecuencias de la intercepción de una carta. Por eso la pregunta para Standhartinger es averiguar cómo eran las estructuras de comunicación con las que tenían que lidiar las personas que estaban presas en aquellos tiempos. Importante para ella es saber cómo se podía escribir, qué se podía decir en un contexto de vigilancia extrema, de censura. Porque es claro que el escrito no llega primero a sus destinatarios, sino a las manos de los guardias y los jueces ${ }^{33}$ y otros vigilantes. Para la autora, el discurso de Pablo implica tomar en cuenta estos riesgos y esperar un escrito cuyo discurso sea un tanto ambiguo. Por otro lado, habría que tomar en cuenta también que los destinatarios de la carta, es decir, la comunidad cristiana de Filipos, tendría que saber interpretar lo que el Apóstol intentaba decir en su carta. Esto significa, entre otras cosas, leer entre líneas y distinguir dos discursos, uno público y otro escondido.

Standhartinger, para analizar los riesgos de enviar cartas y las estrategias que los prisioneros usaban en sus escritos, retoma los aportes de James C. Scott en su libro Domination and the Arts of Resistance. Hidden Transcripts $^{34}$. Para un análisis del discurso de Pablo en su carta a los Filipenses esto es fundamental, porque se tendría que tener en cuenta el doble discurso: el público y el escondido. De esa manera se comprendería mejor la falta de información, los vacíos, ambigüedades o códigos debido a la cesura.

James Scott, en su libro que acabamos de mencionar, da herramientas para ayudar a leer, interpretar y entender mejor ciertas conductas políticas de grupos subordinados, cuando estos que no tienen poder están frente a los poderosos y se ven obligados a adoptar estrategias para sobrevivir. Para ello, Scott busca sacar a la luz las tensiones, contradicciones y posibilidades inherentes en las relaciones de poder asimétricas. Si bien Scott hace su análisis a partir de las relaciones de poder entre grupos sociales, su análisis sirve muy bien para el estudio de textos como cartas de prisión, como bien lo ha percibido y aplicado Standhartinger.

Escribir en la prisión era peligroso, hay testimonios de muertes debido a interpretaciones hechas por encargados que según ellos hablaban

${ }^{33} \mathrm{Ibid}$, p. 145.

${ }^{34}$ O. c. 
contra el emperador ${ }^{35}$. La vigilancia era permanente y no era extraño que hubiera espías enviados de parte del César para recabar información de actitudes contrarias al emperador. Tiberio y Nerón eran muy susceptibles a las críticas, y por esa razón se abusaba del delito de maiestas. Con Augusto, señala Standhartinger, comenzó una red de seguridad interna; se trataba de la policía secreta de Roma; esta labor de espionaje también se daba en las provincias por medio de los gobernadores. Como en los tiempos de represión de las dictaduras modernas, había una lista de personas sospechosas. Se daba el caso de soldados que, vestidos de civil, iniciaban conversaciones contra el emperador con el objetivo de ver si la persona con la cual estaban hablando caía en la trampa de hablar mal del emperador para luego ser arrestada y llevada a la cárcel y ponerla en cadenas ${ }^{36}$.

Por esa razón, los documentos que se escribían en la prisión tenían que escribirse de manera muy cuidadosa, sin llamar la atención sobre posibles interpretaciones sediciosas o para no ser acusados de criticar al emperador. Por eso no son raros los mensajes ocultos, ambiguos, con vacíos; o los pseudónimos, incluso escribir en otro idioma fuera del latín era preferible ${ }^{37}$. En palabras de Standhartinger:

Puesto que las cartas estaban en riesgo de ser leídas incluso por perseguidores, se hicieron intentos de opacar su contenido. En la antigüedad ya se tenían sistemas de escritura secreta y de criptografía. Las técnicas de ocultamiento incluían presentar un contenido tan opaco como fuera posible, había el uso de pseudónimos, juegos de palabras, acertijos o el hecho de escribir en otro idioma. 38

Filipenses es una carta escrita desde la prisión por un preso que experimenta una gran incertidumbre frente a su juicio y posible condena, una situación de vida o muerte. Para un análisis de su discurso no se puede pasar por alto esta realidad.

Por otro lado, también tenía implicaciones para los destinatarios, pues frases, palabras o nombres explícitos podrían comprometerlos. Y es

${ }^{35}$ A. Standhartinger, «Aus der Welt eines Gefangenen», a. c., p. 156.

36 Ibid., p. 157.

37 Ibid., p. 158.

${ }^{38} \mathrm{Ibid}$. La autora incluye la siguiente cita de Cicerón escrita a su amigo Atticus: «Pero escribo esto apurado, y ciertamente tengo miedo de decir demasiado. En las próximas cartas escribiré todo con claridad, si encuentro un mensajero totalmente confiable, o, si no, si escribo oscuramente, ustedes entenderán a pesar de todo. En esas cartas tomaré el nombre de Laelius y tú Furius. El resto estará en lenguaje

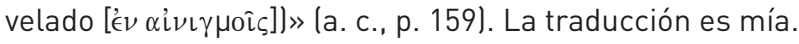


que, como indica Standhartinger, estar en contacto con los prisioneros considerados subversivos era también riesgoso. No solo por la vergüenza de tener un amigo o pariente en cadenas, sino por la comunicación vigilada por las autoridades. Los espías de la policía secreta romana estaban presentes en todos lados. Por eso había que ser precavidos en la comunicación de los mensajes. Cualquier cosa sospechosa que se dijera podía ser utilizada en su contra. Llama la atención que en los inicios del cristianismo encontramos viudas y huérfanos que se encargaban de dar asistencia a los cristianos encarcelados por su $\mathrm{fe}^{39}$; sin desconocer que los líderes también visitaban a los prisioneros, no deja de sorprendernos que las viudas y los huérfanos, así como los ancianos, tuvieran también esta tarea.

Pasemos ahora a analizar algunos detalles importantes de la carta a los Filipenses, vista desde esta perspectiva.

\section{La carta a los Filipenses}

\subsection{Introducción a la carta}

La discusión sobre si Filipenses está compuesta por una o tres car$\operatorname{tas}^{40}$ la vamos a dejar de lado. En este artículo nos concentramos en ver su discurso tal y como está presentado en la redacción final que aparece en el canon del NT. En cuanto al lugar geográfico desde donde escribe, Pablo no indica en su carta la ciudad donde está preso, así que las opciones que se tomen al respecto serán siempre inciertas. Las propuestas más comunes son Éfeso y Roma; también se ha propuesto Cesarea. Roma y Éfeso son los lugares más frecuentes propuestos como lugares donde se escribió la carta a los Filipenses; ambas presentan argumentos tanto favorables como en contra. No vamos a exponer todos los argumentos conocidos entre los expertos en Filipenses, para ello remitimos a los comentarios existentes. Nosotros nos inclinamos por Éfeso, nos convence la cercanía entre Filipos y Éfeso, que permite una comunicación más fluida, además de que creemos que, cuando Pablo escribió a los corintios sobre sus problemas en la cárcel

${ }^{39}$ En la carta de Luciano de Samosata a Cronio, cuando habla contra los cristianos, menciona esta práctica de asistencia a los cristianos presos, entre ellos a las viudas y a los huérfanos: «... y desde el amanecer se podía ver junto a la cárcel, esperando, a grupos de ancianos, viudas y huérfanos...», en Obras II. Sobre la muerte de Peregrino. Madrid, Gredos, 1990, p. 246.

${ }^{40}$ Las tres cartas, llamadas A, B y C, serían: A: 4,10-20; B: 1,1-3,1; C: 3.2-4.9. 
en Asia Menor (2 Cor 1,8-10), estaba aludiendo a su experiencia cuando escribió Filipenses: Éfeso está en Asia Menor. Posiblemente, cuando Pablo había sido condenado a muerte y por alguna razón la condena no prosperó, salió libre ${ }^{41}$ y pudo contar su experiencia a los hermanos de Corinto (cf. 1 Cor 15,32). En cuanto a fechas, si se escribió desde una cárcel en Roma, sería entre el 60 y el 62, después de la carta a los Romanos; si se escribió desde una cárcel en Éfeso, sería entre el 52 y el 54, bajo los emperadores Tiberio o Nerón.

Es importante tener en cuenta que Filipo era una colonia romana, donde sus habitantes eran en su mayoría veteranos de guerra, lo cual garantizaba los intereses del imperio. Su ubicación era bastante estratégica, pues era atravesada por la Vía Egnatia, estaba cerca del mar y tenía yacimientos de oro y plata. Sus habitantes eran ciudadanos romanos, pero también había griegos y tracios, la población nativa. Los romanos, señala Lilian Portefaix ${ }^{42}$, eran los que ocupaban los puestos oficiales y los principales empleadores de campesinos. También eran los mayores propietarios de los esclavos, los cuales abundaban en el campo. Por ser colonia, en la población había no pocos veteranos de guerra que habían llegado en distintas oleadas $^{43}$. Se trataba de los militares que recibían tierras como pago por sus servicios en el ejército romano.

Tomar muy en cuenta a los destinatarios de una carta escrita desde la prisión que viven en una colonia con exmilitares del imperio cobra muchísima importancia. Ello conlleva el riesgo de ser considerado cómplice al ser amigo de un preso visto como enemigo de la sociedad romana y sus gobernantes. Por otro lado, no solo los destinatarios del escrito corrían peligro, sino sobre todo las personas cercanas que le llevaban ayuda, visitaban a los presos o recibían correspondencia. Timoteo y Epafrodito son quienes están en posición delicada y deben tomar precauciones al visitar a Pablo en la prisión. Alguien ha sugerido que tal vez Epafras, el compañero de prisión de Pablo cuando escribió Filipenses, es el mismo que el Epafrodito de Filipenses, lo cual podría significar que fue también arrestado cuando visitó a Pablo. Pero de eso no estamos seguros, lo que Pablo dice en su carta es que estuvo a punto de morir debido a una enfermedad $(2,27)$, aunque

${ }^{41}$ Según A. Standhartinger, era frecuente la amnistía cuando había cambio de emperador, podría ser que, al subir Nerón al trono, concediera libertad a los presos encerrados por sus ideas, como Pablo (a. c., p. 150).

42 Sisters Rejoice. Paul's Letter to the Philippians and Luke-Acts as Seen by Firstcentury Philippian Women. Upsala, Tryckkontakt, 1988, pp. 59-67.

43 Ibid., p. 60. 
también dice que por causa de Cristo estuvo a las puertas de la muerte. En cuanto al riesgo que corren los destinatarios de la carta, llama la atención la falta de información de un nombre de persona. Cuando Pablo exhorta a Evodia y Síntique a que tengan el mismo sentir, alude a alguien sin mencionar su nombre para que ayude a estas dos líderes a que se pongan de acuerdo. Le llama «mi compañero fiel», literalmente: «genuino compañero

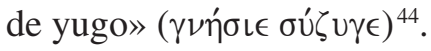

Como el análisis de su discurso está condicionado por el contexto de la prisión, nuestro análisis será contextual. Primero describiremos el contexto deducido desde la carta, o sea, el marco global que permite ubicar la situación. Seguidamente analizaremos el discurso tomando en cuenta tres aspectos importantes: la situación física y emocional de Pablo, su teología, considerando la prisión o las cadenas como el locus teológico, y las exhortaciones a la comunidad de Filipo.

\subsection{El marco global}

Para situar mejor estos tres aspectos es importante tener presente el marco global que produce la carta, o lo que podría también llamarse: la situación retórica.

Pablo está en cadenas debido a la proclamación del evangelio $(1,13)$. El hecho de que esté preso indica que la policía romana ve un peligro en las proclamas de Pablo. Por eso lo han privado de la libertad. La pregunta que se viene a la mente es: ¿qué peligro podría generar el evangelio para el Imperio romano? La respuesta tendría que ser algo que desestabiliza el imperio y su poder o que daña la imagen del emperador. Pablo menciona en su carta dos cuestiones políticas muy atrevidas. La primera aparece en el himno cristológico, donde el énfasis, como indica Cassidy, no estaría en el vaciamiento de Cristo y su humildad, sino en la parte de la exaltación, donde Dios le da un nombre sobre todo nombre, es decir, más alto que el del emperador romano, para que, ante Jesús, el Cristo, el Crucificado por las leyes del Imperio romano, todos los seres tanto celestiales como terrenales y subterráneas se arrodillen y lo proclamen como el Señor.

La otra cuestión tiene que ver con la propuesta de un estilo de vida a contracorriente con el del Imperio romano. Un estilo de vida diferente al de

\footnotetext{
${ }^{44}$ Algunas versiones transcriben el nombre dando por sentado que se llamaba «Sícigo» (Biblia de Jerusalén), pero no contamos con nombres iguales en la antigüedad. Es más probable que aluda al compañero genuino, fiel o incondicional.
} 
la sociedad grecorromana, a la cual cataloga de «torcida y perversa» $(2,15)$. Esto se observa en las exhortaciones que le hace a la comunidad de creyentes de Filipos. En medio de esa sociedad torcida y perversa, los seguidores del movimiento del Resucitado deben hacer la diferencia, ser luces, «brillar como estrellas en el mundo» $(2,15)$. El estilo de vida que propone relativiza totalmente el privilegio de la ciudadanía romana, proponiendo una ciudadanía celestial (3.20), no para vivirla después de la muerte, sino para vivir de una manera diferente, de acuerdo a los valores del reinado de Dios $(1,27)$, bajo la soberanía de otro Señor, que es Jesucristo. Valores que se alejan del sistema de patronazgo al no considerarse superiores a los demás $(2,3)$ y a dejar la ambición personal $(2,3)$. Pablo está en contra del estilo de vida de aquellos ciudadanos romanos en Filipo cuya visión se reduce al interés propio, a las cosas banales y vergonzosas $(3,19)$. A estos les llama enemigos de la cruz $(3,18)$. Seguramente, para un romano, el que una persona crucificada por ellos mismos fuera venerada les parecería la cosa no solo más extraña y ridícula, sino peligrosa.

Aparte de la oposición que lo puso en cadenas, es decir, los romanos, hay en Éfeso otro frente que predica el evangelio, pero que no piensa igual que Pablo en relación con el contenido del evangelio. Eso es normal, en todos los movimientos que buscan un cambio de la sociedad hay divisiones en cuanto a su pensamiento. Pablo no dice exactamente en qué consiste la visión teológica de estos otros proclamadores del evangelio, pero algo tiene que ver con las cadenas de Pablo. Podría ser que no estén de acuerdo con el tinte político que Pablo muy abierta y arriesgadamente le confiere al rol del Crucificado como Señor del universo entero, por encima del Cé$\operatorname{sar}^{45}$. Lo que le ha convertido en un preso. Y, además, como las cadenas eran una señal de vergüenza, sería un mal testimonio, tal vez a aquellos no les parece que un cristiano esté en cadenas. También podía ser lo contrario, como lo fue más tarde, que el hecho de sufrir martirio daba autoridad a quien lo sufría. Pablo simplemente lo que dice con respecto al otro frente es que anuncian a Cristo por envidia y rivalidad $(1,15)$, y más abajo dice

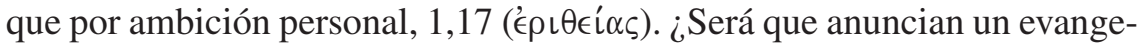
lio menos comprometedor? Lo que parece claro es que el asunto de las cadenas está presente en esta problemática. En Éfeso es claro que hay miedo de parte de la comunidad cristiana, Pablo lo dice abiertamente: el hecho de que él esté en cadenas ha hecho posible que gente que piensa como él «se atreva mucho más a hablar la palabra», es decir, el mensaje $(1,14)$. Estos lo hacen por amor, dice, porque saben que por la defensa del evangelio ha

${ }^{45}$ Cf. R. CAssidy, Paul in Chains, o. c., pp. 178-184. 
sido puesto en cadenas $(1,16)$. Y quienes por «ambición personal» lo anuncian, según Pablo lo hacen para causarle una mayor aflicción a sus cadenas $(1,17)$. De todas maneras, esta situación no le preocupa tanto como la hostilidad de parte del Imperio romano. Por eso, sabiamente, no le da importancia a estas fracciones entre predicadores, porque, para Pablo, lo más importante es dar a conocer a Cristo. Lo que sí llama la atención es que sea la comunidad cristiana de Filipos, que está más lejos de la prisión, quien está ayudando a Pablo, y no haya mención de las comunidades de Éfeso.

Hay tres frentes o grupos de oposición a los ideales de Pablo y de la comunidad de Filipos: primero está la sociedad romana, llamada aquí «torcida y perversa» por seguir valores no acordes con los que proclama el evangelio de Pablo; segundo, el grupo de predicadores que se distancian de Pablo por su forma extrema de predicarlo, lo cual lo ha llevado a las cadenas; y tercero, el frente de los judaizantes, que difiere aún más de este segundo grupo en cuando a la propuesta de salvación y sus requerimientos $(3,1)$. Los filipenses tienen que cuidarse del primero y del tercero. El segundo se encuentra en la ciudad donde Pablo está preso.

Ahora veamos la situación de los destinatarios. La comunidad de Filipos, muy probablemente romana por vivir en esa colonia, está pasando también por dificultades; puede ser que la policía romana la esté vigilando y/o la gente circunvecina le sea muy hostil por profesar otras creencias, consideradas nocivas. Este sector que se les opone (’ُ $\left.\nu \tau \iota \kappa \in \iota \mu \epsilon^{\prime} \nu \omega \nu\right)$ les pasa intimidando $(1,28)$. Por eso están muy preocupados y angustiados $(4,6)^{46}$. Por otro lado, si tomamos en cuenta lo que dice Hechos en 16,22-24, los filipenses seguramente guardaban en la memoria el terrible encarcelamiento que sufrió Pablo justamente por tener otra propuesta de vida diferente a la romana. Tal vez esa situación fortaleció los lazos de amistad y solidaridad con el Apóstol. Al enterarse de que Pablo estaba preso, le han enviado una ayuda económica, ya que los presos dependían de amigos y familiares para sobrevivir, y ellos lo saben bien. Esta ayuda económica a Pablo no era la primera vez que se la enviaban. Pablo recuerda la solidaridad que tuvieron más de una vez, desde que él se fue, empezando cuando estaba en Tesalónica (Flp 4,15-16), cuando no estaba preso.

${ }^{46}$ Recordemos que, según Hch 16,22-24, años atrás, al inicio de la fundación de la comunidad, la gente de Filipos había acusado a Pablo y a Silas de hablar de costumbres inaceptables de aceptar y practicar para los romanos; y por ese motín que se hizo, las autoridades los mandaron desnudar, azotar severamente, meterlos en el cuarto más terrible de la cárcel y encadenarlos con un cepo (Hch 16,22-24). Los convertidos seguramente tenían ya este testimonio de Pablo en su mente cuando supieron que nuevamente estaba preso, pero en Éfeso (o Roma). 
Posiblemente, la situación de la comunidad cristiana de Filipos se puso más difícil porque se han solidarizado con Pablo, que está preso $(1,7)$; hasta la comunidad le ha enviado a uno de sus miembros, Epafrodito, con el dinero para las necesidades de Pablo en la prisión (4,10-19). Para colmo, Epafrodito se puso muy grave, al borde de la muerte, allí donde Pablo estaba $(2,27)$. Pablo les manda a Epafrodito, que ya está mejor; posiblemente es él quien lleva la carta. A los filipenses les gustaría mucho que Pablo les enviara a Timoteo para fortalecerles, pero Pablo no puede ahora, porque Timoteo es imprescindible para él en esos momentos para su defensa, donde la incertidumbre reina en cuanto a su condena o liberación $(1,23)$. Epafrodito les llevará noticias de Pablo.

La comunidad de creyentes en Filipos, liderada especialmente por mujeres, está pasando también por divisiones internas. Dos grandes líderes, Evodia y Síntique, tienen algunos desacuerdos $(4,3)$. Pablo les exhorta a que se pongan de acuerdo, ayudadas por un mediador, compañero de trabajo de mucha confianza de Pablo ( $\sigma u ́ \zeta u \gamma \epsilon)$. Pablo no quiere dar su nombre posiblemente para protegerlo de la censura ${ }^{47}$.

La correspondencia entre Pablo y la comunidad de Filipos se ha vuelto crucial para tener noticias de lado y lado, para dar alegría y aliviar un poco la tensión de la inseguridad. El apóstol se anima ( $\epsilon \dot{v} \psi v \chi \hat{\omega})$ al recibir noticias de ellos $(2,19)$. Pablo utiliza unos vocativos muy amorosos hacia los filipenses: amados, añorados, mi corona, mi alegría, hermanos míos, etc. No es para menos, hay detrás una relación fuerte y sólida de amistad y lucha conjunta. Evodia y Síntique lucharon junto ( $\left.\sigma \nu \nu \eta \dot{\theta} \theta \lambda \sigma^{\prime} \alpha \nu\right)$ con Pablo en lo referente al evangelio, lo mismo Clemente y otros compañeros de trabajo ( $\sigma \nu \nu \in \rho \gamma \omega \hat{\omega})$ ) (4,2-3). La carta, como se puede ver, utiliza muchas imágenes militares, algunos han estudiado este aspecto de la carta. Para nosotros es claro, pues, tratándose de un prisionero político, su militancia político-religiosa sale a flote en su lenguaje metafórico.

Pablo, como un líder del movimiento del Resucitado, que fue a dar a la cárcel por sus ideas y que ve que su postura pone en peligro también a las comunidades que le escuchan, necesita escribirles a los creyentes de Filipos no solo para agradecerles la ayuda económica, sino para consolarles, fortalecerles, tranquilizarles, darles seguridad y exhortarles a que resistan y permanezcan unidos, defendiendo la causa del evangelio, a pesar de la oposición.

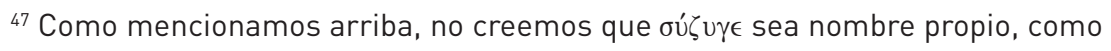
algunos proponen. 


\subsection{Situación física y emocional de Pablo en cadenas}

Pablo habla poco de sus sufrimientos en la prisión. Por eso, para hablar de su situación física, debemos leer entre líneas y visualizarlo en la prisión. Según el análisis visto arriba, Pablo padece la custodia militar (custodia militaris), ya que tiene visitas como Timoteo y Epafrodito, y puede recibir dinero. Este tipo de custodia consistía en estar encadenado a uno o más soldados, ya por los brazos, manos (manacles) o piernas y pies (pedicles), lo cual era bastante incómodo. La carta tuvo que haberla dictado, o pagarle al soldado para que le liberara un rato mientras escribía. En su carta habla del pretorio. Si Pablo está en Éfeso, se trataría de un lugar dentro del palacio del gobernador. Las prisiones, indica Wansink, no solo se daban en edificios construidos exclusivamente para prisioneros, sino cualquier edificio podía funcionar como prisión para algunos. El extraño saludo al final, «de los de la casa del César», si no era una estrategia o código de Pablo para pasar la censura, se trataría de esclavos del gobernador que se han familiarizado con Pablo y tal vez también con Timoteo y Epafrodito. Esto nos hace pensar que tal vez le hayan hecho la vida menos dura en la prisión. En 1,17 no niega el sufrimiento en la prisión al señalar que el grupo rival que predica por ambición personal cree añadirle más sufrimiento a sus cadenas. Además, es muy probable que Pablo haya pasado hambre. En 4,12 indica que ha aprendido el secreto ( $\mu \in \mu u ́ n \mu \alpha \iota)$ de pasar hambre y no solo de pasarla bien. Ha sido su experiencia la que le ha llevado a arreglárselas en cualquier necesidad $(4,11)$.

En cuanto a su situación emocional y psicológica, podemos percibir a través de la carta varias cosas: su fuerza en la debilidad, su experiencia de vivir en la incertidumbre con respecto a la condena y su preocupación por sus destinatarios frente a su ausencia, y la hostilidad que enfrentan.

$\mathrm{Su}$ fuerza interior y firmeza la podemos percibir en 1,20, cuando dice: tengo «la absoluta seguridad de que ahora y siempre Cristo manifestará su gloria en mi persona, tanto si estoy vivo como si estoy muerto». En 2,17 , cuando exhorta a los filipenses a que brillen en medio de la sociedad perversa $(2,15)$, afirma: «Y aunque tuviera que sufrir el martirio como ofrenda sacrificial en favor de vuestra fe, me sentiría dichoso compartiendo con todos vosotros mi alegría; alegraos igualmente vosotros de compartir conmigo vuestra alegría». Pablo está seguro de lo que cree de sus ideales, siente la fuerza del Espíritu de Jesucristo $(1,19)$, por sus convicciones, por su fe, ha luchado y está dispuesto a dar la vida. La experiencia de Pablo encadenado nos ayuda a entender lo que había expresado a los corintios en su segunda carta: «Por eso me complazco en mis flaquezas, en las injurias, 
en las necesidades, en las persecuciones y en las angustias sufridas por Cristo; pues, cuando estoy débil, entonces es cuando soy fuerte» (2 Cor 12,10).

Uno de los problemas de las personas privadas de libertad es el manejo del tiempo, la incertidumbre de lo que va a pasar con ellas después del juicio. Pablo experimenta esta situación de incertidumbre, no sabe si lo van a condenar a muerte o a dejar en libertad. Él confía que saldrá libre por las oraciones en su favor $(1,19)$, tiene confianza en que puede suceder, si es que no lo dice para tranquilizar a sus destinatarios $(1,25.26)$; y aunque Pablo añora estar con Cristo, prefiere la libertad a la muerte para ayudar a la comunidad de Filipos $(1,22)$. Sin embargo, la reiteración de la posibilidad de la condena a muerte es más fuerte, y pareciera que Pablo se está preparando para este desenlace: para mí -dice-, «la vida es Cristo y la muerte, una ganancia» $(1,21$; cf. 2,17$)$.

Pablo habla mucho de gozo; la palabra y sus derivados se repiten 16 veces. Esta es una de sus estrategias para darle consuelo, fortaleza y esperanza a sus destinatarios. Sin embargo, como es de esperar, la tristeza no está ausente, incluso el deseo de morir. Esto es normal en prisioneros políticos. La tristeza de la prisión la menciona Pablo cuando Epafrodito cae gravemente enfermo. Dios lo sana, dice en 2,27, por compasión no solo hacia Epafrodito, sino también hacia él, «no queriendo añadir más tristeza

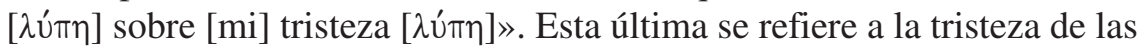
cadenas. Ya mencionamos antes el deseo de Pablo de estar con Cristo, es decir, el de morir. Pero en ese caso da la impresión de que se trata de aceptar con valor la condena a muerte, de él no depende la decisión en el juicio. Sin embargo, en 1,22 hay algo interesante que poquísimos exegetas han notado, y que Wansink, después de su análisis de las prisiones en la antigüedad, lo hace ver. En ese versículo, Pablo no sabe qué escoger, si vivir o morir. La mayoría de los comentarios no toman en serio el sujeto activo del verbo, literalmente dice: «Si el vivir en la carne esto para mí es fruto de trabajo [= será provechoso para el trabajo], no sabría $[\gamma \nu \omega \rho$ í $\zeta \omega]$ qué escoger $[\alpha i \rho \eta ́ \sigma o \mu \alpha \iota] »$. Esta frase concentra la decisión solo en Pablo, como sujeto activo de los verbos $\alpha i \rho \eta ́ \sigma o \mu \alpha \iota$ у $\gamma \nu \omega \rho i \zeta \omega$. Si no fuera porque se trata del líder del movimiento del Resucitado, cualquiera pensaría que tiene en mente el suicidio, cosa frecuente en los prisioneros del tiempo del imperio, como vimos antes. Si queremos ver a Pablo como el sujeto del verbo «elegir», y tomar literalmente lo que dice, habría que pensar, como Wansink, en una muerte voluntaria pasiva. Esto significa que no se va a defender como debe en el momento del juicio. Pensar esto no está fuera de lugar, porque entraría en la imitación de Jesús. En el juicio ante Pilato, según la 
versión de Mateo, Jesús decide guardar silencio y no defenderse ante las acusaciones. Esto propició la inmediata condena a muerte.

Sin embargo, racional y emocionalmente, lo que le preocupa a Pablo no es su situación, sino la de sus destinatarios, los filipenses, que se sienten intimidados y perseguidos más por los romanos que por el grupo de los judaizantes. Su angustia mayor es por su amada comunidad de creyentes que está en Filipos. El grueso de la carta lo dedica a animarles, fortalecerles, exhortarles y aconsejarles para que se mantengan firmes y fieles al evangelio que conocen por medio de Pablo, lo cual exige tomar posición frente a los valores dominantes de la sociedad imperial romana. Por otro lado, tener que cuidarse en todo lo que dice en la carta para que pase la censura por la cual pasaban los escritos que salían de la prisión no permitía sentirse libre de expresar todo lo que deseaba, tenía que escribir de manera opaca o ambigua, con la esperanza de que sus destinatarios pudieran entender lo que les decía entre líneas.

\subsection{La teología que surge de su experiencia como prisionero: gracia y praxis}

En Pablo se da una dialéctica: la gracia y la praxis no se contradicen. Todo depende de Dios, pero eso no evade la lucha por la defensa del evangelio. Si bien, como cualquier judío, Pablo cree que todo ocurre por voluntad de Dios, en su caso particular en la prisión esto ocurre con más fuerza. La dependencia de Dios, podríamos decir, es absoluta; el estar en cadenas y sentirse impotente lo exige ${ }^{48}$. Dios está en todo: los filipenses son excelentes colaboradores en la proclamación y defensa del evangelio, pero Dios es quien ha comenzado y perfeccionado esa obra en los filipenses $(1,6)$; la salvación es algo por lo cual se trabaja para que todos la alcancen, pero es Dios el que actúa el querer y el hacer $(2,12-13)$, por la obra de Cristo se arriesga la vida, así lo ha hecho Epafrodito también al solidarizarse con Pablo (2,30). Pablo ha ganado a Cristo porque él fue encontrado por Cristo $(3,9)$. Aquí se ubica el debate con los judaizantes, que depositan su confianza en la propia ley, en la identidad cultural, considerada superior a los demás; eso para Pablo no es lo importante, lo ha dejado atrás (3,5-7), ha optado por otra manera de ser y de vivir, donde Jesucristo reina como soberano de una manera diferente a la del emperador, sobre todo en relación

${ }^{48}$ Cf. otros prisioneros políticos como Bonhoeffer, Frei Betto, Mandela, Karl Gaspar y otros. 
con sus súbditos o vasallos, los ciudadanos romanos. El gobierno de Jesucristo se fundamenta en la justicia de la gracia, donde la misericordia prima en el juicio de Dios. De manera que Pablo decidió encaminar su vida, su práctica y actitudes guiado por un horizonte más amplio que lo lleva a depender absolutamente de la gracia de Dios en medio de la hostilidad y la muerte. La fuerza que le ayuda a seguir bajo ese horizonte es el modelo de la vida de Jesucristo, reflejada en el himno cristológico de 2,6-11, posiblemente prepaulino.

Según el himno, Jesús padeció todas las cosas peores que un ser humano puede padecer: se hizo esclavo, se dejó humillar y fue condenado a la muerte de cruz, que era la peor y más humillante muerte en tiempos del imperio. Pero el juicio de Dios fue diferente al de las leyes romanas, y lo reivindicó: lo exaltó en extremo, lo puso como Señor del universo, y con eso le quitó la autoridad a todos los poderes de la tierra. Así, la vida, muerte y resurrección de Jesucristo le da razón a su existencia en la prisión. Ese es su gran anhelo, el poder de la resurrección del Crucificado es lo que le da la fuerza de seguir vivo, pues espera resucitar también de entre los muertos (v. 11). Pablo se mueve y resiste la prisión por esa promesa. Por eso sigue adelante $(\delta\llcorner\omega ́ \kappa \omega)$ imitando a Cristo, intentando ser como él, buscando ser íntegro en su plenitud ( $\tau \in \lambda \in \operatorname{ló} \omega)(3,12)$.

Por esta forma de convivir, llamada ciudadanía celestial, vale la pena luchar por ella contra la corriente dominante. Implica dejar lo que es valioso a la luz de la sociedad tanto judía (ley, circuncisión) como romana (banquetes y otras cosas materiales) y lanzarse hacia adelante, como al vacío $(3,13)$. Pablo lo hizo, pues está seguro de que llegará a la meta como un atleta que focaliza el trofeo al final de su carrera $(3,13-14)$.

Por eso hay que ver la gracia de Dios en el padecimiento de las cadenas. En su cuerpo encadenado, Cristo es engrandecido $(1,20)$, el Crucificado se hace presente, porque él es la causa de que esté preso. Pablo siente en carne propia la solidaridad del Crucificado en su padecimiento en la cárcel, por eso dice: «... quiero compartir sus padecimientos y conformar mi muerte con la suya» $(3,10)$. No por un sentido masoquista, sino porque $\mathrm{Pa}$ blo se ha aferrado a la promesa de la resurrección. De hecho, eso es lo que más anhela; en el mismo versículo expresa: «Quiero conocer a Cristo, experimentar el poder de su resurrección», y en el siguiente $(3,11)$ : «Espero así participar de la resurrección de entre los muertos».

Pablo vive y actúa bajo la fe en que pronto llegará el verdadero Salvador, y el sufrimiento tendrá su fin, pues «el Señor está cerca» $(4,5)$. Por eso se aguarda ansiosamente $\left(\dot{\alpha} \pi \epsilon \kappa \delta \delta^{\prime} \chi 0 \mu \alpha \iota\right)$ al Salvador $(3,20)$, que viene del cielo, el que es verdadero y gobierna a los que se comportan como ciu- 


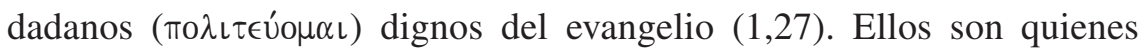
comparten la ciudadanía que vale a los ojos de Dios $(3,20)$. Esta ciudadanía $(\pi \circ \lambda i \tau \epsilon \cup \mu \alpha)$ llamada celestial no es extraterrestre, sino otra manera de vivir y de ser aquí en la historia, opuesta a la ciudadanía romana ${ }^{49}$, esta se vive bajo la espera del final de los tiempos. Dos veces aparece «el día de Cristo» haciendo alusión al fin de la historia, y las dos tienen que ver con la praxis que será juzgada. La primera se refiere a la práctica que los filipenses comenzaron y que Dios la perfeccionará hasta el final $(1,6)$, la otra aparece dentro de la exhortación a los filipenses de que se sean luz en medio de la sociedad perversa y mantengan firmes la palabra de vida, para que, en «el día de Cristo», Pablo salga airoso y quede al descubierto que no trabajó por el evangelio en vano $(2,15-16)$. Por lo pronto, él quiere ser como Cristo, con la esperanza de que su cuerpo en cadenas, vergonzoso y humillado a los ojos de la sociedad, sea transformado con gran poder en un cuerpo glorioso $(3,21)$. Esa será la reivindicación que el Señor hará con Pablo, esa esperanza le ayuda a resistir los sufrimientos y humillaciones de la prisión.

\subsection{Exhortaciones a los destinatarios}

Los destinatarios son probablemente en su mayoría mujeres, grandes líderes y valientes ${ }^{50}$. Ellas, junto con otros líderes varones, como Clemente y el misterioso amigo fiel, están al frente de la comunidad cristiana en Filipos. Están angustiados por la situación de Pablo en la prisión y el peligro que corre Epafrodito, tanto por su enfermedad como por visitar a un preso «político». Hacen un gran esfuerzo para poder solidarizarse con él económicamente, porque también es una comunidad con pocos recursos. También, dijimos, están siendo intimidados por gente del lugar, que se oponen al evangelio proclamado por ellos. Posiblemente, la hostilidad viene también porque se rehúsan rendir culto al César, y proponen otra conducta, que choca con su forma de conducirse. Pablo se angustia por ellos. En su carta se esmera por hacerles llegar tranquilidad y consuelo: «No se

${ }^{49}$ Cf. R. CAssidy, Paul in Chains, o. c., pp. 194-195.

${ }^{50}$ Potefaix escribe su libro Sister Rejoice, desde la teoría de la recepción de textos literarios, y su lectura la orienta desde el punto de vista de la recepción de las mujeres de Filipos. Ella analiza el trasfondo cultural y religioso de las mujeres de Filipos, porque considera que las mujeres eran las principales destinatarias de la carta. 
preocupen...» $(\mu \epsilon \rho \iota \mu \nu \alpha ́ \omega, 4,6)$, les dice; el término griego tiene que ver con la preocupación y ansiedad que ocurre cuando se percibe un daño o desgracia; por eso les asegura que Dios les va dar una paz más allá de toda comprensión y de toda lógica $(4,7)$. Pablo les insiste en que tomen con alegría esta dura situación, y les exhorta a no desfallecer en la opción que han hecho por el evangelio de Jesucristo, el Dios de paz les acompañará $(4,9)$.

Además de la exhortación de que se alegren, el Apóstol les suplica que se mantengan firmes ( $\sigma \tau \eta ́ \kappa \epsilon \tau \epsilon) ~(1,2 ; 4,1)$, y sobre todo que permanezcan unidos, teniendo el mismo pensamiento $\left(\phi \rho \nu^{\prime} \in \omega\right)$. Desde el primer capítulo, la unidad es recalcada en la exhortación con diferentes términos; en

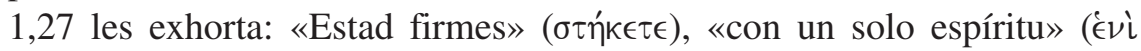

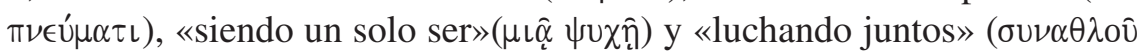
$\nu \tau \epsilon \varsigma)$. Con gran solemnidad inicia el segundo capítulo $(2,1-2)$ rogándoles de nuevo para que estén unidos; para él eso es tan importante que le colmará de una gran alegría: si tienen un mismo sentir o manera de pensar ( $\phi \rho \circ \nu \hat{\eta}$

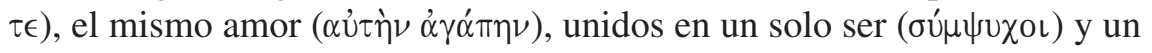

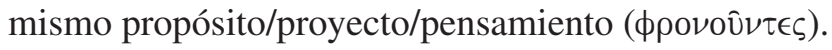

Tener el mismo sentir y pensar apunta al evangelio, al que llama aquí «palabra de vida» $(2,16)$. Es esta palabra la que deben mantener o creer con firmeza $\left(\epsilon^{\prime} \in \dot{\ell} \chi \omega\right)$. La situación de peligro amerita que no haya divisiones dentro de la comunidad, por eso Evodia y Síntique deben buscar la reconciliación y ponerse de acuerdo, el contacto de confianza de Pablo (el amigo

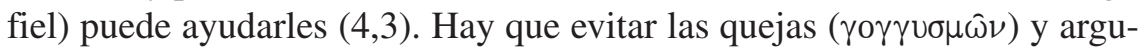
mentaciones $(\delta\llcorner\alpha \lambda \circ \gamma\llcorner\sigma \mu \hat{\omega} \nu)$ dentro de la comunidad $(2,14)$, para no debilitarse como movimiento unido y ser más vulnerables frente los adversarios.

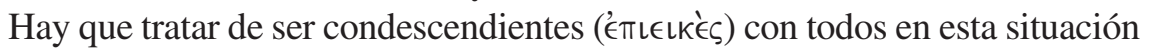
de opresión, pues el Señor está cerca $(4,5)$.

Además de mantener el espíritu alto, alegrarse, estar unidos y mantenerse firmes en sus creencias, Pablo les exhorta a estar atentos, a discernir para tener clara la naturaleza de las cosas ( $\alpha i \sigma \theta \eta \dot{\sigma} \sigma \iota)$, a que comprueben

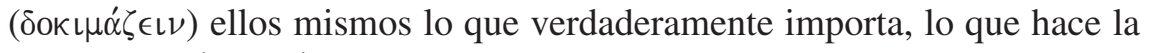
diferencia ( $\tau \dot{\alpha} \delta\llcorner\alpha \phi \epsilon ́ \rho \nu \tau \tau)$, a que sean intachables y puros, y llenos de fru-

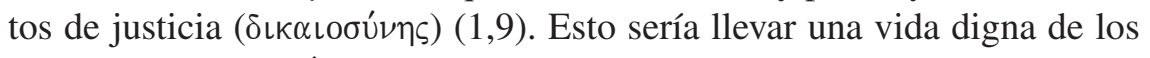

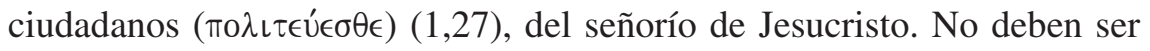
imitadores de quienes piensan solo en sí mismos en sus propios intereses y placeres, los romanos, llamados aquí «enemigos de la cruz» $(3,18)$, cuyo modelo de vida es el emperador (en este caso sería Nerón), cuyos súbditos los persiguen u hostigan $(1,28)$. Al contrario, deben comportarse como hijos de Dios, irreprochables, y así poder ser estrellas o antorchas en medio de «una generación torcida y perversa» $(2,15)$. 
Las oraciones y súplicas tanto de Pablo como de la comunidad de Filipos son fundamentales para cobrar fuerzas en la resistencia contra quienes causan el sufrimiento $(1,4.19 ; 4,6)$. Pablo les recuerda a los filipenses con realismo que ellos también pueden padecer, pues están librando la misma lucha que él (1,29-30), de ahí las exhortaciones a la unidad, al amor, a mantenerse firmes, a luchar juntos, a tener un mismo objetivo. El Espíritu del Resucitado (1,19), el Cristo $(4,13)$, es quien da la fuerza en todo para seguir.

\subsection{Prisioneros políticos modernos}

Hoy día contamos con cartas modernas del siglo xx escritas desde la prisión. Entre la gente conocida mundialmente que fue encarcelada por sus ideas y que escribió cartas desde su fe cristiana y/o desde la resistencia frente las injusticias de su sociedad tenemos a Dietrich Bonhoeffer (preso desde 1943 hasta su ejecución en 1945), miembro del grupo de resistencia contra la dictadura de Hitler; Frei Betto (preso desde 1969 hasta 1973), dominico encarcelado por su resistencia contra la dictadura de Brasil; Karl Gaspar, de la orden de los redentoristas, preso durante la dictadura de Marcos en Filipinas, y Nelson Mandela (preso desde 1964 hasta 1990), líder de la resistencia contra el apartheid de Sudáfrica ${ }^{51}$.

Al leer las cartas de estas personas encontramos ciertas constantes que se repiten y nos hace pensar en la posibilidad de contar con otro género literario catalogado como cartas desde la prisión. La carta a los Filipenses ha sido clasificada últimamente como «carta de amistad»o «carta de amistad y finanzas ${ }^{52}$, de acuerdo a la tipografía de la epistolografía romana. Sin embargo, no nos parece suficiente, porque no se está tomando seriamente en cuenta el contexto desde donde se escribe y la experiencia del prisionero. Se hace necesario postular un nuevo tipo de carta, «cartas desde la prisión». Se trataría de cartas escritas por personas encarceladas por sus ideas, es decir, por pensar de forma diferente al status quo. Se trataría de cartas de prisioneros políticos, pero no solo políticos, sino también por prisioneros comunes encarcelados injustamente.

${ }^{51}$ Escogí cartas de hombres porque Pablo es varón y la situación de mujeres en las cárceles es diferente; a su sufrimiento de privación de la libertad se le añade el relacionado a la humillación debido a su sexo y cuerpo femenino. El caso de las mártires Felicidad y Perpetua en la cárcel es obvio.

${ }^{52}$ A. Loveday (1989); B. Witherington (1994), G. Fee (1995) y otros. 
Bonhoeffer, Mandela, Gaspar y Frei Betto hablan desde una gran fuerza interior, relativizan las cosas materiales, viven bajo la incertidumbre en cuanto a su condena y juicio, se preocupan constantemente más por los que están fuera, teologizan a partir de su experiencia como privados de libertad y su posible fin, les exhortan y están dispuestos a morir por sus ideales. Vemos algunos ejemplos similares al discurso salido de Pablo como prisionero.

\section{Conclusión}

En este artículo hemos analizado la carta a los Filipenses desde la perspectiva de un prisionero que hoy llamaríamos «político». Pablo sería un líder del movimiento del Resucitado. Vimos cómo eran las cárceles en la antigüedad, en tiempos del Imperio romano, la custodia militar que padeció Pablo y lo peligroso que podría ser un escrito salido de la prisión. A partir de allí hicimos una propuesta del marco global en que surge el escrito, tomando en cuenta los ideales de Pablo enmarcados en su concepto de evangelio, resumido en una propuesta nueva de estilo de vida acorde con el Crucificado que fue exaltado por Dios y puesto como Señor de una nueva humanidad. Propuesta a contracorriente del Imperio romano. Vimos también los oponentes o adversarios de su propuesta de evangelio, así como los destinatarios y su situación delicada y difícil frente a la hostilidad de sus conciudadanos. Bajo ese marco global analizamos la carta, deduciendo de su discurso: el estado físico y emocional del apóstol en tanto prisionero político, su teología surgida a partir de las cadenas como locus teológico y las exhortaciones a la comunidad de Filipos a alegrarse en medio de la adversidad, a mantenerse firmes, unidos; a discernir lo que verdaderamente vale y a poner en práctica una manera de conducirse ciudadanamente de manera diferente a la de sus conciudadanos romanos.

Elsa TÁmez 